\title{
Activation and thermal stability of ultra-shallow B+-implants in Ge
}

Yates, B. R.; Darby, B. L.; Petersen, Dirch Hjorth; Hansen, Ole; Lin, Rong; Nielsen, P. F.; Romano, L.; Doyle, B. L.; Kontos, A.; Jones, K. S.

Published in:

Journal of Applied Physics

Publication date:

2012

Document Version

Publisher's PDF, also known as Version of record

Link back to DTU Orbit

Citation (APA):

Yates, B. R., Darby, B. L., Petersen, D. H., Hansen, O., Lin, R., Nielsen, P. F., Romano, L., Doyle, B. L., Kontos, A., \& Jones, K. S. (2012). Activation and thermal stability of ultra-shallow B+-implants in Ge. Journal of Applied Physics, 112(12).

\section{General rights}

Copyright and moral rights for the publications made accessible in the public portal are retained by the authors and/or other copyright owners and it is a condition of accessing publications that users recognise and abide by the legal requirements associated with these rights.

- Users may download and print one copy of any publication from the public portal for the purpose of private study or research.

- You may not further distribute the material or use it for any profit-making activity or commercial gain

- You may freely distribute the URL identifying the publication in the public portal

If you believe that this document breaches copyright please contact us providing details, and we will remove access to the work immediately and investigate your claim 


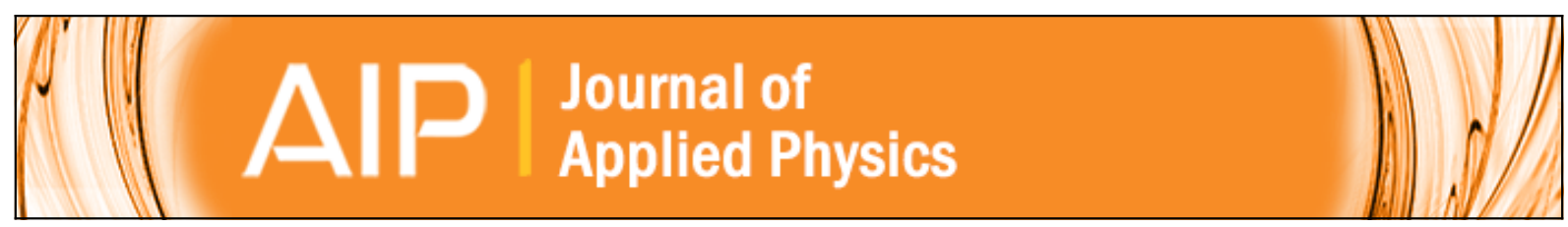

\section{Activation and thermal stability of ultra-shallow B+-implants in Ge}

B. R. Yates, B. L. Darby, D. H. Petersen, O. Hansen, R. Lin, P. F. Nielsen, L. Romano, B. L. Doyle, A. Kontos, and K. S. Jones

Citation: Journal of Applied Physics 112, 123525 (2012); doi: 10.1063/1.4770474

View online: http://dx.doi.org/10.1063/1.4770474

View Table of Contents: http://scitation.aip.org/content/aip/journal/jap/112/12?ver=pdfcov

Published by the AIP Publishing

\section{AlP Re-register for Table of Content Alerts}




\title{
Activation and thermal stability of ultra-shallow $\mathrm{B}^{+}$-implants in $\mathrm{Ge}$
}

\author{
B. R. Yates, ${ }^{1, a)}$ B. L. Darby, ${ }^{1}$ D. H. Petersen, ${ }^{2}$ O. Hansen, ${ }^{2,3}$ R. Lin, ${ }^{4}$ P. F. Nielsen, ${ }^{4}$ \\ L. Romano, ${ }^{5}$ B. L. Doyle, ${ }^{6}$ A. Kontos, ${ }^{7}$ and K. S. Jones ${ }^{1}$ \\ ${ }^{1}$ Department of Materials Science and Engineering, University of Florida, Gainesville, Florida 32611, USA \\ ${ }^{2}$ DTU Nanotech, Department of Micro- and Nanotechnology, Technical University of Denmark, \\ DK-2800 Kgs. Lyngby, Denmark \\ ${ }^{3} \mathrm{CINF}$, Center for Individual Nanoparticle Functionality, Technical University of Denmark, \\ DK-2800 Kongens Lyngby, Denmark \\ ${ }^{4}$ CAPRES A/S, Scion-DTU, DK-2800 Kgs. Lyngby, Denmark \\ ${ }^{5}$ IMM-CNR MATIS and Dipartimento di Fisica e Astronomia, Università di Catania, Via S. Sofia 64, \\ I-95123 Catania, Italy \\ ${ }^{6}$ Sandia National Laboratories, MS-1056, Albuquerque, New Mexico 87185, USA \\ ${ }^{7}$ Applied Materials, Gloucester, Massachusetts 01930, USA
}

(Received 4 September 2012; accepted 27 November 2012; published online 27 December 2012)

\begin{abstract}
The activation and thermal stability of ultra-shallow $\mathrm{B}^{+}$implants in crystalline (c-Ge) and preamorphized $\mathrm{Ge}(\mathrm{PA}-\mathrm{Ge})$ following rapid thermal annealing was investigated using micro Hall effect and ion beam analysis techniques. The residual implanted dose of ultra-shallow $\mathrm{B}^{+}$ implants in Ge was characterized using elastic recoil detection and was determined to correlate well with simulations with a dose loss of $23.2 \%, 21.4 \%$, and $17.6 \%$ due to ion backscattering for 2,4 , and $6 \mathrm{keV}$ implants in $\mathrm{Ge}$, respectively. The electrical activation of ultra-shallow $\mathrm{B}^{+}$ implants at 2, 4, and $6 \mathrm{keV}$ to fluences ranging from $5.0 \times 10^{13}$ to $5.0 \times 10^{15} \mathrm{~cm}^{-2}$ was studied using micro Hall effect measurements after annealing at $400-600^{\circ} \mathrm{C}$ for $60 \mathrm{~s}$. For both c-Ge and PA-Ge, a large fraction of the implanted dose is rendered inactive due to the formation of a presumable B-Ge cluster. The B lattice location in samples annealed at $400{ }^{\circ} \mathrm{C}$ for $60 \mathrm{~s}$ was characterized by channeling analysis with a $650 \mathrm{keV} \mathrm{H} \mathrm{H}^{+}$beam by utilizing the ${ }^{11} \mathrm{~B}(\mathrm{p}, \alpha) 2 \alpha$ nuclear reaction and confirmed the large fraction of off-lattice B for both c-Ge and PA-Ge. Within the investigated annealing range, no significant change in activation was observed. An increase in the fraction of activated dopant was observed with increasing energy which suggests that the surface proximity and the local point defect environment has a strong impact on B activation in Ge. The results suggest the presence of an inactive B-Ge cluster for ultra-shallow implants in both c-Ge and PA-Ge that remains stable upon annealing for temperatures up to $600^{\circ} \mathrm{C}$. (C) 2012 American Institute of Physics. [http://dx.doi.org/10.1063/1.4770474]
\end{abstract}

\section{INTRODUCTION}

As the length scales associated with complementary metal oxide semiconductor (CMOS) devices continue to shrink, it has become evident that the physical limitations of silicon have been reached and the adoption of a replacement material will be increasingly important for future device generations. Silicon firmly established itself as the preferred material for CMOS devices for several decades due to the exceptional qualities of its thermally grown oxide and the properties of the $\mathrm{Si} / \mathrm{SiO}_{2}$ interface. ${ }^{1}$ However, with the industry transferring from the poly-Si/SiO ${ }_{2}$ to metal gate/ high- $\kappa$ dielectrics for the gate stack to compensate for physical scaling limitations, the ability to efficiently integrate alternative active semiconducting materials in CMOS devices is becoming closer to reality.

Due to its enhanced electron and hole mobility and reduced contact resistance compared to $\mathrm{Si}, \mathrm{Ge}$ is an attractive replacement material and has gained a substantial focus over the last decade. ${ }^{2-4}$ In recent years, several studies have inves-

\footnotetext{
a) Author to whom correspondence should be addressed. Electronic mail: bradyates@ufl.edu.
}

tigated the electrical behavior of ion implanted $\mathrm{B}$ in both crystalline (c-Ge) and preamorphized (PA-Ge) Ge ${ }^{5-11}$ Similar to $\mathrm{Si}$, it has been shown that preamorphization increases dopant activation during the solid phase epitaxial growth (SPEG) process. ${ }^{6}$ In addition, a modest $360^{\circ} \mathrm{C}$ anneal results in a high level of boron activation ${ }^{7}$ which remains stable for anneals up to $550{ }^{\circ} \mathrm{C}$ for $1 \mathrm{~h} .{ }^{9}$ However, the majority of the experiments published in the literature have used high energy $\mathrm{B}^{+}$implants that are not directly relevant for ultrashallow junctions.

In order to realize the junctions necessary to continue the physical scaling of devices, it is necessary to fully understand dopant diffusion and electrical activation of ultra-shallow implants. B is known to diffuse very slowly in Ge which makes it an ideal candidate for future pMOS devices. ${ }^{12-14}$ However, there is a large knowledge gap regarding the electrical activation for these technologically relevant implants. A few reports have studied the activation behavior of ultrashallow $\mathrm{B}^{+}$implants in Ge and have observed a high level of dopant incorporation and thermal stability over a range of annealing conditions, similar to deeper implants. ${ }^{15-19}$ However, these studies relied on sheet resistance $\left(R_{S}\right)$ measurements in conjunction with chemical profiles and mobility 
models to determine activation values. The Hall effect enables a direct measurement of active carriers and mobility and has been utilized to characterize ultra-shallow implants in $\mathrm{Ge}^{20,21}$ Interestingly, it has been shown that the activation of $2 \mathrm{keV}$ $\mathrm{B}^{+}$implants $\mathrm{Ge}$ has an anomalous activation behavior which is characterized by an incomplete activation independent of implanted fluence for both c-Ge and PA-Ge. ${ }^{20}$ The behavior is believed to be due to a B-Ge cluster formation which renders a large fraction of the implanted fluence inactive. Although far less pronounced, the presence of B-Ge clusters has been reported previously, but has only been observed for implants into c-Ge. ${ }^{9,15,16,22}$ For $\mathrm{Si}$, the formation and evolution of boron-interstitial clusters are well-characterized and understood, ${ }^{23-26}$ but to date, a comprehensive study has not been completed for $\mathrm{B}^{+}$implants in Ge.

In this work, a systematic study of the effect of isochronal annealing on the electrical activation and subsequent clustering behavior of ultra-shallow $\mathrm{B}^{+}$implants in $\mathrm{Ge}$ is presented. Ion beam analysis techniques and transmission electron microscopy are used to further explain the electrical behavior observed upon annealing.

\section{EXPERIMENTAL METHODS}

Experiments were performed on Czochralski-grown n-type Ge (001) wafers with resistivity larger than $50 \Omega \mathrm{cm}$. Samples were $\mathrm{B}^{+}$implanted at 2,4 , and $6 \mathrm{keV}$ with fluences ranging from $5.0 \times 10^{13}$ to $5.0 \times 10^{15} \mathrm{~cm}^{-2}$ at $0^{\circ}$ tilt and twist. An identical set of PA-Ge samples was produced by first implanting a $\mathrm{Ge}^{+}$fluence of $2.0 \times 10^{14} \mathrm{~cm}^{-2}$ at $120 \mathrm{keV}$ prior to $\mathrm{B}^{+}$implantation to produce an amorphized surface layer to a depth of $100 \mathrm{~nm}$ as verified by high-resolution cross-sectional transmission electron microscopy (HR-XTEM). The beam current was fixed at $1.1 \mathrm{~mA}$ for all $\mathrm{B}^{+}$implants and the platen was held at $25^{\circ} \mathrm{C}$. Samples were processed in a Heatpulse 4100 rapid thermal annealer (RTA) in an $\mathrm{N}_{2}$ ambient at $400-600{ }^{\circ} \mathrm{C}$ for $60 \mathrm{~s}$ to activate the implanted B. HR-XTEM was completed using a JEOL $2010 \mathrm{~F}$ to image the microstructure of specimens before and after annealing. TEM samples were prepared using a FEI DB235 focused ion beam.

It has been speculated that a large fraction of the implanted $\mathrm{B}^{+}$fluence is lost to ion backscattering. ${ }^{20}$ To characterize the as-implanted chemical dose of ultra-shallow $\mathrm{B}^{+}$implants in $\mathrm{Ge}$, a set of variable energy samples were implanted at 2, 4, and $6 \mathrm{keV}$ and characterized using elastic recoil detection (ERD). Samples were characterized as-implanted to avoid any issues introduced with further processing. Any losses due to backscattering would be independent of implanted dose; therefore, a dose of $5.0 \times 10^{15} \mathrm{~cm}^{-2}$ was used to increase measurement counts and decrease experimentation time for all implant energies investigated. ERD characterization was performed using the ${ }^{11} \mathrm{~B}\left({ }^{28} \mathrm{Si},{ }^{11} \mathrm{~B}\right)$ reaction with a $28 \mathrm{MeV} \mathrm{Si}^{4+}$ beam with the Ge target tilted at $75^{\circ}$ from incidence and a recoil angle of $30^{\circ}$. A $12 \mu \mathrm{m}$ mylar foil was used to shield forward scattered $\mathrm{Si}$ ions and to allow the recoiled $\mathrm{B}$ atoms to enter the detector. The areal density of implanted boron was calculated using a spectral scaling approach that accounts for the changes in the recoil cross section and stopping powers with depth. ${ }^{27}$
Micro Hall effect measurements were used for their ability to accurately measure the electrical properties of ultrashallow junctions. ${ }^{28-30}$ Micro Hall effect characterization was completed using a CAPRES microRSP M-150 M4PP fitted with Au-coated probes, a probe spacing of $20 \mu \mathrm{m}$, and a permanent magnet with a magnetic flux density of $0.475 \mathrm{~T}$. Hall sheet number $\left(n_{H}\right)$ and mobility values $\left(\mu_{H}\right)$ were adjusted to obtain the carrier sheet number $\left(n_{S}\right)$ and drift mobility $\left(\mu_{d}\right)$ by using a scattering factor $\left(r_{H}\right)$ of 1.21 as determined empirically. ${ }^{7}$ The carrier density and drift mobility are related to the Hall values by $n_{s}=n_{H} \times r_{H}$ and $\mu_{d}=\mu_{H} / r_{H}$, respectively.

$\mathrm{B}$ in Ge cannot be detected by standard Rutherford backscattering spectrometry since the lower atomic number of $B$ with respect of Ge. Nuclear reaction analysis (NRA) is an ion beam technique to detect $\mathrm{B}$ atoms in Ge by measuring the yield of $\alpha$ particles from the reaction ${ }^{11} \mathrm{~B}(\mathrm{p}, \alpha){ }^{8} \mathrm{Be}$, which has a broad resonance near the proton energy of 650 keV. ${ }^{31-35}$ NRA and channelling measurements along the $\langle 100\rangle,\langle 110\rangle$, and $\langle 111\rangle$ axes were performed using the ${ }^{11} \mathrm{~B}(\mathrm{p}, \alpha){ }^{8} \mathrm{Be}$ reaction (proton energy of $650 \mathrm{keV}$ ) on the $\mathrm{B}$ implanted samples. The $\alpha$ particles detector was placed at $160^{\circ}$ with respect to the incident beam direction and it was covered with a $10-\mu \mathrm{m}$-thick aluminised mylar film to prevent backscattered protons to reach the detector. A second detector, at $165^{\circ}$, was used to detect protons backscattered from $\mathrm{Ge}$ atoms and to perform the alignment procedure. The normalized channelling yield $\chi\left(\chi^{\mathrm{Ge}}\right.$ and $\chi^{\mathrm{B}}$, for host Ge and $\mathrm{B}$ atoms, respectively) is defined as the ratio of the aligned yield to the yield of randomly directed beam. $\chi^{\mathrm{B}}$ was obtained from the energy integrated $\alpha$ particles yield normalized to the random yield and is proportional to the fraction of $\mathrm{B}$ displaced out of lattice, $\chi^{\mathrm{Ge}}$ was measured just below the surface peak of the backscattered proton spectrum. The uncertainty of $\chi$ is statistically determined by the number of counts in the aligned spectrum. The minimum yield $\chi_{\min }$ is the yield obtained for perfect alignment of the incident beam with crystal direction normalized to the yield for random incidence. If the non-substitutional impurity atoms occupy random lattice positions, the impurity $\chi$ has similar values along the several crystal axes, in this case, the apparent substitutional fraction $f_{s}$ is defined as

$$
f_{s}(B)=\frac{1-\chi_{\min }^{B}}{1-\chi_{\min }^{G e}} .
$$

\section{RESULTS AND DISCUSSION}

To confirm the residual implanted dose of ultra-shallow $\mathrm{B}^{+}$implants in $\mathrm{Ge}$, samples as-implanted to a dose of $5.0 \times 10^{15} \mathrm{~cm}^{-2}$ were characterized using ERD. The residual implanted dose for samples implanted at 2, 4, and $6 \mathrm{keV}$ was found to be $3.84 \times 10^{15} \mathrm{~cm}^{-2}, 3.88 \times 10^{15} \mathrm{~cm}^{-2}$, and $4.12 \times 10^{15} \mathrm{~cm}^{-2}$, respectively. The deviation from the implanted dose is significant as the loss is in excess of $20 \%$ of the implanted dose for the lowest implant energy. As speculated in the previous reports, it is believed that ion backscatter is a large source of dose loss and at first inspection could 
seemingly reduce the activation of the $\mathrm{B}^{+}$implant. ${ }^{20}$ Due to the low atomic mass relative to $\mathrm{Ge}$ and the $1 / \mathrm{E}^{2}$ dependence of backscattering, boron is highly susceptible to ion backscattering during low-energy implantation which reduces the chemical dose before any other processing is completed. Taking into account that samples were characterized asimplanted, it is assumed that the deviation from implanted dose is due completely to backscattering losses during implantation. Boron is known to diffuse very slowly in $\mathrm{Ge}^{12-14}$ and no further significant dose loss is expected due to surface desorption following annealing at $400-600^{\circ} \mathrm{C}$ for $60 \mathrm{~s}^{36}$

Fig. 1 shows the percentage of implanted $\mathrm{B}^{+}$lost to backscattering as a function of implant energy as measured with ERD plotted in conjunction with SRIM simulations. ${ }^{37}$ The simulations compare favorably with the dose loss values experimentally determined through ERD and confirm that a large fraction of the implanted dose is lost to ion backscattering. Given that backscattering is an energy-dependent phenomenon, it is assumed that this behavior is identical for lower doses. The experiment confirms that SRIM simulations are sufficient for estimating the retained implanted dose for ultra-shallow $\mathrm{B}^{+}$implants in Ge.

Fig. 2 shows the sheet resistance $\left(R_{S}\right)$ and sheet number $\left(n_{s}\right)$ for samples implanted at 2,4 , and $6 \mathrm{keV}$ to $\mathrm{B}^{+}$fluences ranging from $5.0 \times 10^{13}$ to $5.0 \times 10^{15} \mathrm{~cm}^{-2}$ after annealing for $400{ }^{\circ} \mathrm{C}$ for $60 \mathrm{~s}$. In Figs. 2(a) and 2(b), it is evident that $R_{S}$ decreases with increasing fluence and energy for both c-Ge (diamonds) and PA-Ge (circles). Following a $400{ }^{\circ} \mathrm{C} 60$ s anneal, the minimum $R_{S}$ achieved was 45.9 and $105.9 \Omega / \mathrm{sq}$ for PA-Ge and c-Ge, respectively. The lower $R_{S}$ values for PA-Ge with respect to c-Ge have been documented previously ${ }^{6,15,20}$ and are due to increased B incorporation upon SPEG. The decrease in $R_{S}$ with increasing implant energy can be explained by the increase in the number of active carriers as evidenced in Figs. 2(c) and 2(d).

In Figs. 2(c) and 2(d), sheet number (as adjusted using $\left.r_{H}=1.21\right)$ is plotted as a function of implant fluence. It is evident that the decrease in $R_{S}$ with increasing fluence is due

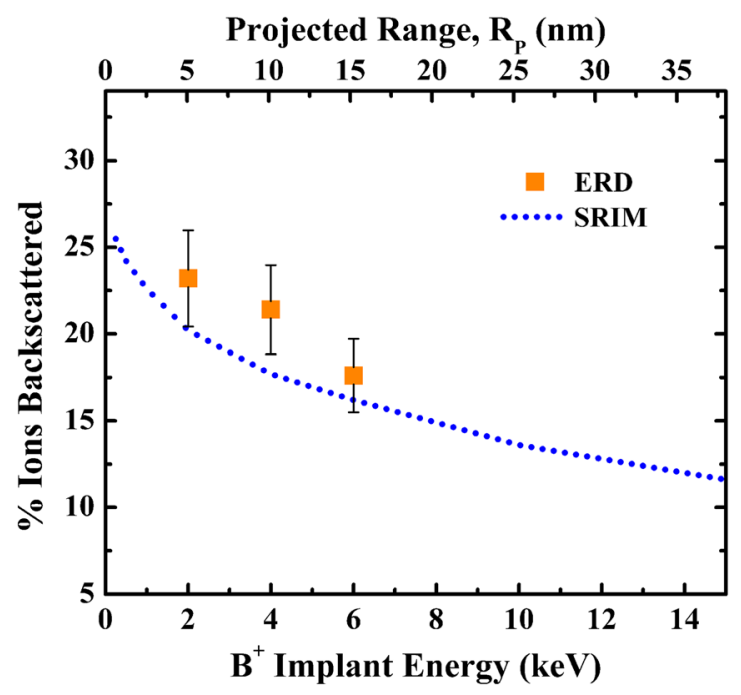

FIG. 1. Percent of B ions backscattered as a function of implant energy into c-Ge as simulated by SRIM and experimentally determined through ERD for a $5.0 \times 10^{15} \mathrm{~cm}^{-2}$ implant into Ge. to an increase in the overall number of active dopants. For $5.0 \times 10^{15} \mathrm{~B}^{+}-\mathrm{cm}^{-2}$ implants at $6 \mathrm{keV}$, the $n_{s}$ obtained was $7.4 \times 10^{14}$ and $2.2 \times 10^{15} \mathrm{~cm}^{-2}$ for c-Ge and PA-Ge, respectively. The corresponding activation value, defined as the ratio of sheet number divided by the residual implanted fluence, was $18 \%$ and $52 \%$ for c-Ge and PA-Ge, respectively. These low activation values are not entirely surprising given the peak $\mathrm{B}$ concentration, which was simulated by SRIM to be approximately $1.4 \times 10^{21} \mathrm{~cm}^{-3}$ and thus is well above solubility values reported in the literature. ${ }^{7,15,20}$

However, a large difference between the implanted and active fluence also exists for low fluence samples which suggests that a single electrical solubility level does not exist. In conjunction with the anomalous activation behavior of ultrashallow $\mathrm{B}^{+}$implants in $\mathrm{Ge}$ that we have reported previously, ${ }^{20}$ a large discrepancy between the implanted and active fluence exists for both c-Ge and PA-Ge. The incomplete activation at relatively low fluences is believed to be due to the formation of a B-Ge cluster. For the lowest $\mathrm{B}^{+}$fluence of $5.0 \times 10^{13} \mathrm{~cm}^{-2}$ implanted at $2 \mathrm{keV}$, the peak B concentration as simulated by SRIM $^{37}$ is expected to be only $3.0 \times 10^{19} \mathrm{~cm}^{-3}$ which is lower than the reported solubility of B in both c-Ge and PA-Ge. ${ }^{20}$ Despite the low concentration, only a small fraction of dopant is rendered active following a $400{ }^{\circ} \mathrm{C}$ anneal for $60 \mathrm{~s}$. The short annealing time is not the source of the poor activation as our previous work has shown that $400^{\circ} \mathrm{C}$ for $1 \mathrm{~h}$ yielded similar activation values as those documented in this work. ${ }^{20}$

It should be stressed that the decrease from complete activation for the low fluence samples is not due to any electrical solubility argument.

The clustering behavior observed in c-Ge and PA-Ge is well-behaved across the investigated energy range and is intriguing due to its fluence-independent nature. The sheet number values obtained increase as a function of energy which suggests that clustering may increase when the boron profile is located near the surface. Recent reports have documented that the Ge surface acts as a vacancy sink while reflecting interstitials into the bulk. ${ }^{38,39}$ Assuming that this behavior holds true, the near-surface volume should become enriched with interstitials following implantation. This point defect environment would promote the formation of an inactive B-Ge cluster while simultaneously removing vacant lattice sites necessary for B activation. Increasing the implant energy would serve to further reduce the effects of the surface proximity on vacancy annihilation thereby increasing activation which is observed in this work.

It would be expected that B-Ge cluster formation would be dependent on the implanted fluence or overall $\mathrm{B}$ concentration with respect to a solubility limit. If the $\mathrm{B}$ concentrations were to exceed this limit, clustering and inactive dopants would be expected; below this limit, substitutional and active dopants would be the case. It should be noted that the behavior reported in this work is much different from what has been reported previously regarding B clustering in $\mathrm{Ge}^{9,15,16,22}$ for two reasons: (1) Although not as prominent, dose-independent clustering also occurred in ultra-shallow $\mathrm{B}^{+}$implants in PA-Ge and (2) The behavior is independent of fluence and the activation percentage is fixed even for a 

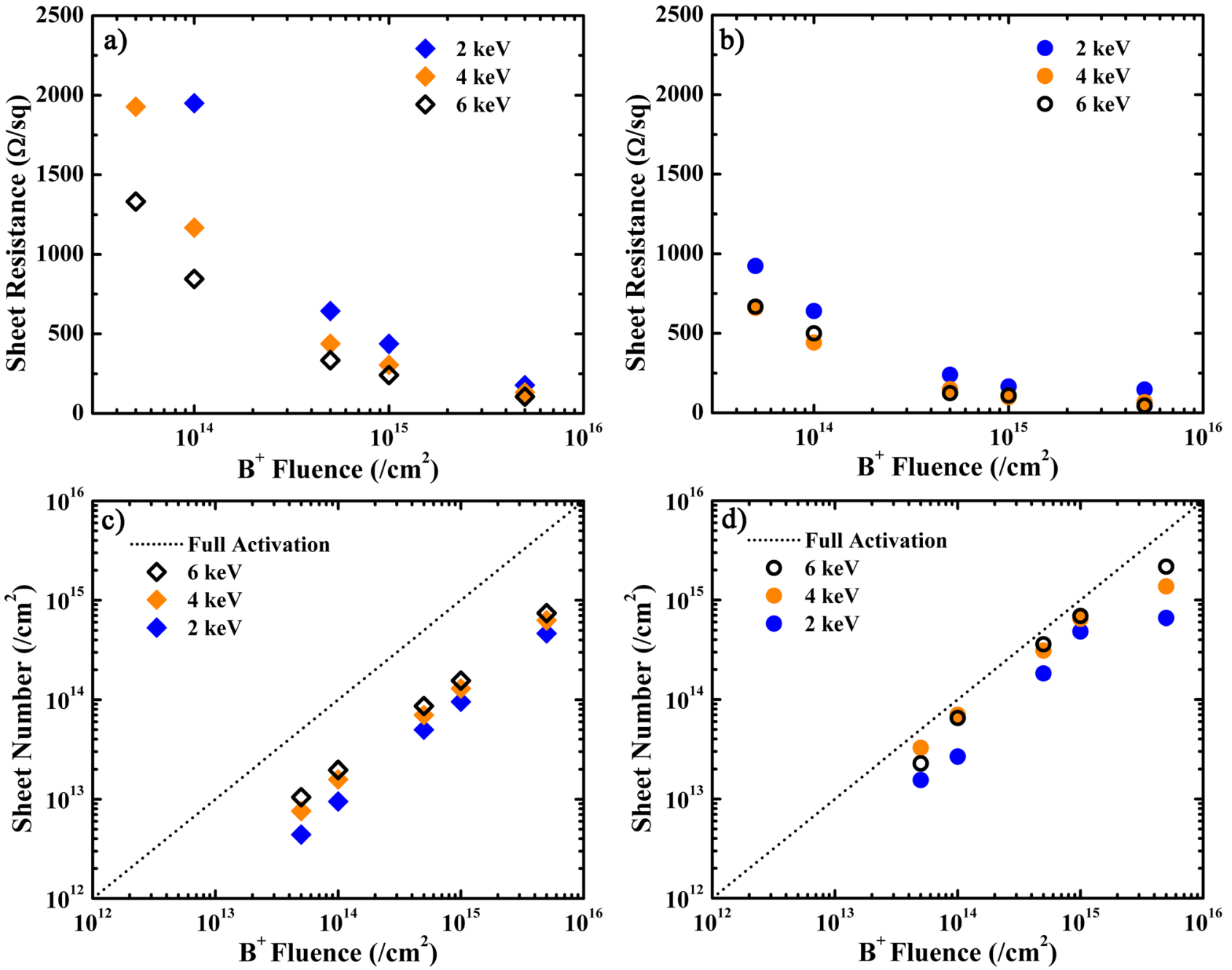

FIG. 2. Measured sheet resistance ((a), (b)) and sheet number ((c), (d)) of samples $\mathrm{B}^{+}$implanted at 2,4 , and $6 \mathrm{keV}$ to fluences ranging from $5.0 \times 10^{13}$ to $5.0 \times 10^{15} \mathrm{~cm}^{-2}$ after annealing $400{ }^{\circ} \mathrm{C} 60 \mathrm{~s}$ in c-Ge ((a), (c)) and PA-Ge ((b), (d)). In (c) and (d), the dotted line represents complete activation.

$5.0 \times 10^{13} \mathrm{~B}^{+}-\mathrm{cm}^{-2}$ implant for both $\mathrm{c}-\mathrm{Ge}$ and PA-Ge. The observed behavior in this work suggests that a single electrically active solubility does not exist for ultra-shallow $\mathrm{B}^{+}$ implants in Ge. Rather, the concentration of active dopants increases with increasing fluence. Since the electrical activation behavior deviates far from what has been observed previously in $\mathrm{Ge}$ as well as in $\mathrm{Si}$, select samples were structurally characterized through channeling analyses utilizing nuclear reactions to determine the substitutional fraction of $\mathrm{B}$ after processing.
Table I shows the fraction of substitutional B as measured using channeling and NRA following a $400{ }^{\circ} \mathrm{C} 60 \mathrm{~s}$ anneal. For both c-Ge and PA-Ge, low and high fluence samples were characterized to obtain structural data on samples that would be expected to be below and above solubility, respectively. For all characterized samples, the normalized channeling yield $\left(\chi^{\mathrm{B}}\right)$ obtained along the $\langle 100\rangle,\langle 110\rangle$, and $\langle 111\rangle$ orientations are all approximately equal. This suggests that the non-substitutional B fraction is randomly distributed throughout the lattice. The substitutional fraction for each

TABLE I. Channeling minimum yields and corresponding substitutional B fraction for $2 \mathrm{keV}$ samples as measured by channeling analysis using nuclear reactions along three axes $(\langle 100\rangle,\langle 110\rangle$, and $\langle 111\rangle)$ and Hall effect measurements after annealing $400^{\circ} \mathrm{C}$ for $60 \mathrm{~s}$.

\begin{tabular}{|c|c|c|c|c|c|c|}
\hline & \multirow[b]{2}{*}{$B^{+}$Fluence $\left(/ \mathrm{cm}^{2}\right)$} & \multirow[b]{2}{*}{$\chi^{B}\langle 100\rangle$} & \multirow[b]{2}{*}{$\chi^{B}\langle 110\rangle$} & \multirow[b]{2}{*}{$\chi^{B}\langle 111\rangle$} & \multicolumn{2}{|c|}{ Active fraction } \\
\hline & & & & & $N R A^{\mathrm{a}}$ & Hall $^{\mathrm{b}}$ \\
\hline \multirow[t]{3}{*}{$\mathrm{c}-\mathrm{Ge}$} & $1.0 \times 10^{14}$ & $0.92 \pm 0.05$ & $0.90 \pm 0.05$ & $0.91 \pm 0.05$ & 9.0 & 11.9 \\
\hline & $1.0 \times 10^{15}$ & $0.81 \pm 0.01$ & $0.83 \pm 0.01$ & $0.84 \pm 0.01$ & 18.3 & 12.0 \\
\hline & $5.0 \times 10^{15}$ & $0.91 \pm 0.01$ & $0.89 \pm 0.01$ & $0.92 \pm 0.01$ & 11.0 & 11.7 \\
\hline \multirow[t]{2}{*}{ PA-Ge } & $1.0 \times 10^{15}$ & $0.41 \pm 0.01$ & $0.39 \pm 0.01$ & $0.43 \pm 0.01$ & 62.0 & 53.9 \\
\hline & $5.0 \times 10^{15}$ & $0.76 \pm 0.01$ & $0.75 \pm 0.01$ & $0.79 \pm 0.01$ & 24.6 & 19.0 \\
\hline
\end{tabular}

${ }^{\mathrm{a}}$ Determined by averaging $\chi^{B}$ values from $\langle 100\rangle,\langle 110\rangle$, and $\langle 111\rangle$ orientations.

${ }^{\mathrm{b}}$ Ratio of carrier sheet density divided by the residual fluence. 
sample was obtained by using Eq. (1) and averaging the channeling yield obtained along each crystal orientation. Assuming that the sheet number obtained from Hall measurements corresponds to the substitutionally located $\mathrm{B}$, the substitutional fractions obtained using channeling analyses and electrical measurements agree favorably for all characterized samples. For even a modest $\mathrm{B}^{+}$fluence of $1.0 \times 10^{14} \mathrm{~cm}^{-2}$ (peak $\mathrm{B}$ concentration of approximately $6.0 \times 10^{19} \mathrm{~cm}^{-3}$ ), the substitutional fractions as measured by Hall and channeling analyses are in agreement at approximately $10 \%$. The results confirm the efficacy of electrical measurements of ultra-shallow $\mathrm{B}^{+}$implants in $\mathrm{Ge}$ and suggest that electrical results obtained using different processing conditions, i.e., different implant fluences or annealing thermal budgets, should be considered to be accurate.

Fig. 3 shows the change in sheet resistance between annealing at $400{ }^{\circ} \mathrm{C}$ and $600{ }^{\circ} \mathrm{C}$ for $60 \mathrm{~s}$. Rather than presenting all measured data, the relative change in $R_{S}$ was used to highlight the trend observed for all implant energies while maintaining a concise plot. Interestingly, with increasing annealing temperature, it was apparent that $R_{S}$ decreased for all c-Ge implant conditions and increased for all PA-Ge implant conditions. As implant fluence was decreased, the relative changes in $R_{S}$ became more prominent for both c-Ge and PA-Ge. For the lowest influence implanted at $2 \mathrm{keV}$ in c-Ge, $R_{S}$ decreased $33.70 \%$ while for the highest fluence $R_{S}$ decreased only $4.86 \%$. A trend of increasing $R_{S}$ was observed between the lowest and highest implanted fluences for PA-Ge as well. The physical origins of this behavior are not entirely clear, but it an be assumed that the changes could be due to the damage imparted to the crystal during implantation as high fluence values into c-Ge and PA-Ge tend towards the same values.

Bruno et al. reported the thermal stability of high energy $\mathrm{B}$ activation following $35 \mathrm{keV}$ implants in Ge with similar annealing conditions $\left(360\right.$ to $550{ }^{\circ} \mathrm{C}$ for $\left.1 \mathrm{~h}\right){ }^{8}$ The data appear to follow a similar trend to what is observed for ultrashallow implants in this work in which $R_{S}$ decreases for c-Ge and increases for PA-Ge. However, it appears to occur to a

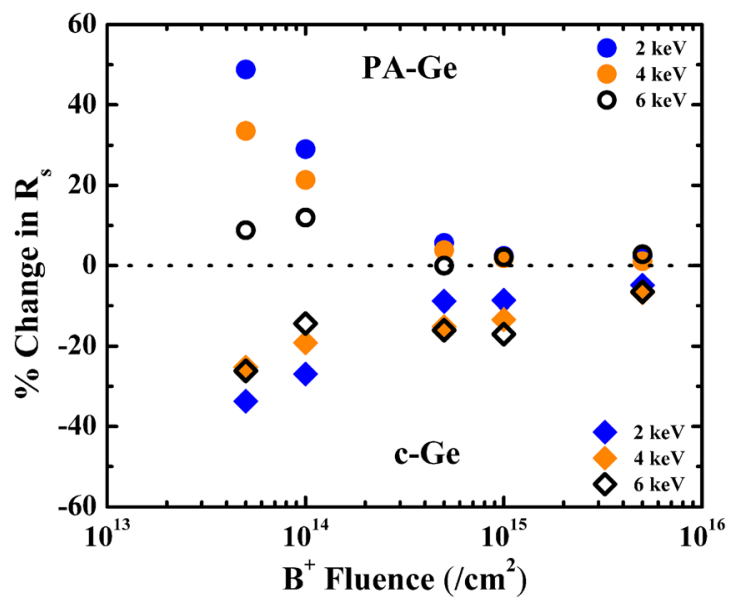

FIG. 3. Change in sheet resistance for 2,4 , and $6 \mathrm{keV} \mathrm{B}^{+}$implants to fluences ranging from $5.0 \times 10^{13}$ to $5.0 \times 10^{15} \mathrm{~cm}^{-2}$ between annealing at $400^{\circ} \mathrm{C}$ and $600^{\circ} \mathrm{C}$ for $60 \mathrm{~s}$. With increased annealing temperature, the data show an increase and decrease in $R_{S}$ for PA-Ge and c-Ge, respectively. lesser extent which is not surprising as the data presented in this work suggests that the trend decreases with implant energy. For example, for a B fluence of $5.0 \times 10^{13} \mathrm{~cm}^{-2}$ into c-Ge, the decrease in $R_{S}$ is $34 \%$ and $26 \%$ for $2 \mathrm{keV}$ and 6 $\mathrm{keV}$, respectively.

Fig. 4 shows the thermal evolution of active carriers and drift mobility for a $\mathrm{B}^{+}$implant to a fluence of $5.0 \times 10^{15} \mathrm{~cm}^{-2}$ into c-Ge and PA-Ge for anneals between 400 and $600{ }^{\circ} \mathrm{C}$. Notably, it should be mentioned that no significant change in activation was observed across the investigated temperature range for both $\mathrm{c}-\mathrm{Ge}$ and PA-Ge samples. Previous reports have shown that the activation of $\mathrm{B}$ in $\mathrm{Ge}$ is remarkably stable. ${ }^{8,10,15,19}$ However, Panciera et al. have reported that the dopant-defect interactions involved with end of range dissolution has an effect on activation values. ${ }^{11}$ The observed changes were slight (approximately $10 \%$ change in activation/deactivation) and suggests that dopantdefect interactions in Ge behave much differently from that which has been extensively studied in $\mathrm{Si}$ in which large fluctuations in activation are observed upon annealing. ${ }^{40}$

In Fig. 4(a), $n_{s}$ is observed to increase with increasing annealing temperature for PA-Ge samples; conversely, $n_{s}$ values slightly decreased for c-Ge samples. Similar to the work by Panciera et al., ${ }^{11}$ the observed changes in activation are subtle and do not have significant effect on the overall activation value. The changes in activation for conditions investigated were on the order of $10 \%$. A significant fraction
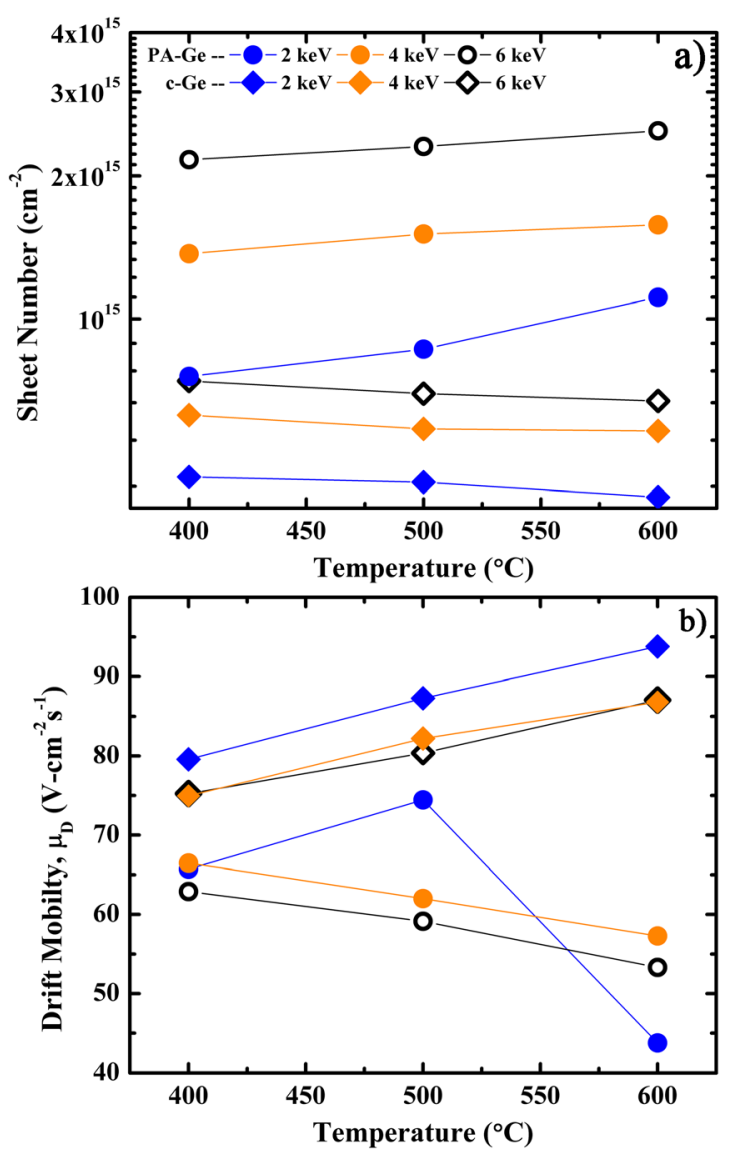

FIG. 4. Measured sheet number (a) and drift mobility (b) as a function of anneal temperature for samples $\mathrm{B}^{+}$implanted at 2,4 , and $6 \mathrm{keV}$ to a fluence of $5.0 \times 10^{15} \mathrm{~cm}^{-2}$ into c-Ge and PA-Ge. 
of the residual implanted dose remained electrically inactive following a $600^{\circ} \mathrm{C}$ anneal for $60 \mathrm{~s}$. These results suggest that the B-Ge cluster responsible for the B inactivity in both c-Ge and PA-Ge is stable at elevated temperatures.

Drift mobility exhibited a contrasting behavior in that values decreased for PA-Ge and increased for c-Ge samples with increasing temperature as shown in Fig. 4(b). The drift mobility decreased with increasing implant energy and annealing temperature for PA-Ge samples which can be explained by the increase in the number of active dopants. It is known that the impact of ionized dopants on mobility is much more significant than that of neutral dopants due to the effects of coulombic scattering. ${ }^{41}$ The increase in $\mu_{D}$ for c-Ge is explained by the reduction of microstructural damage and subsequent reduction in scattering centers as evidenced in Fig. 5.

Fig. 5 shows the microstructure of samples $\mathrm{B}^{+}$ implanted at $2 \mathrm{keV}$ to a fluence of $5.0 \times 10^{15} \mathrm{~cm}^{-2}$ into c-Ge and PA-Ge after annealing for $400-600^{\circ} \mathrm{C}$ for $60 \mathrm{~s}$. It is well known that $\mathrm{B}^{+}$implants into $\mathrm{c}-\mathrm{Ge}$ are characterized by a defective microstructure that near the projected range $\left(R_{P}\right)$ of the implant. ${ }^{9,15,18,19}$ In the case of c-Ge, the layer is not characterized by discernible extended defects, but rather a highly defective microstructure distinguished by inhomogeneous contrast which diminished with increasing annealing temperature. The inability to observe unique defects may be due to several factors. The samples may not have been subjected to a sufficient thermal budget to allow the formation of extended defects or if already formed, they may be very small and high in concentration which limits the ability to view individual defects. ${ }^{42}$ With increasing annealing temperature, the contrast associated with the damaged lattice decreases which suggests that the damage has been reduced. In Fig. 5(c), it is evident that the defective band is much smaller in nature and is located at a depth slightly beyond

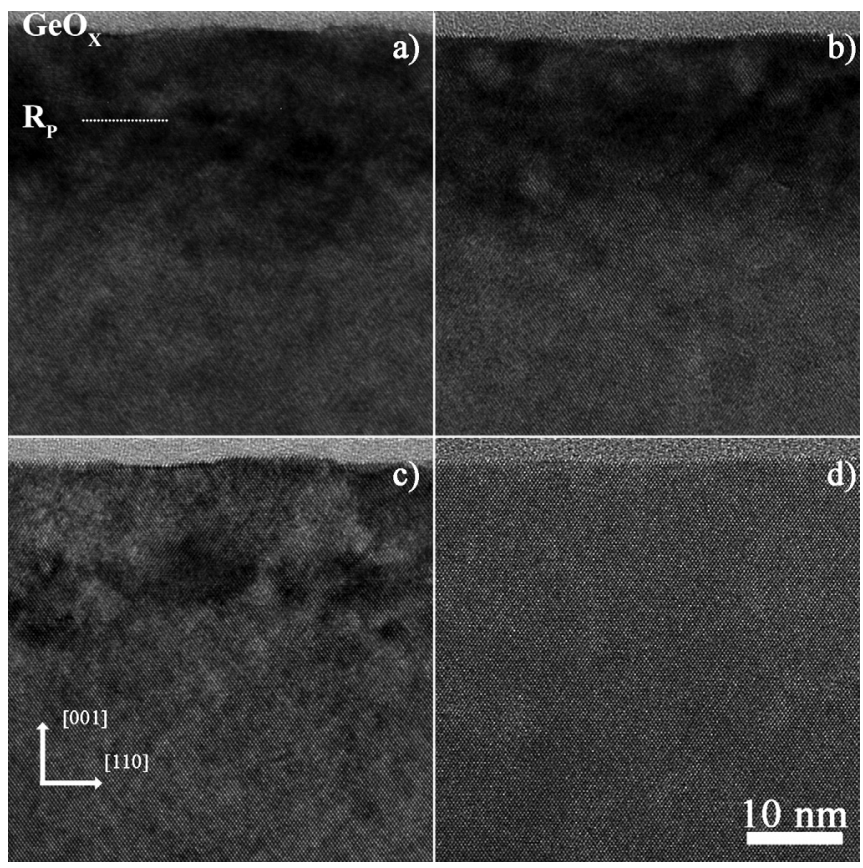

FIG. 5. HR-XTEM images of samples $\mathrm{B}^{+}$implanted at $2 \mathrm{keV}$ to a fluence of $5.0 \times 10^{15} \mathrm{~cm}^{-2}$ into c-Ge after annealing for $60 \mathrm{~s}$ at $400{ }^{\circ} \mathrm{C}$ (a) $500^{\circ} \mathrm{C}$ (b) $600^{\circ} \mathrm{C}$ (c) and into PA-Ge after annealing for $60 \mathrm{~s}$ at $400^{\circ} \mathrm{C}(\mathrm{d})$.
$R_{P}$. The depth of these defects may be due to the forward momentum of the ion beam driving interstitials past the $R_{P}$. Further work is being completed regarding $\mathrm{B}^{+}$implant related defects in c-Ge.

In the case of PA-Ge, the initial amorphous $\mathrm{Ge}(\alpha-\mathrm{Ge})$ layer was approximately $100 \mathrm{~nm}$ (not shown) and is observed to be fully regrown following a $400{ }^{\circ} \mathrm{C}$ anneal for $60 \mathrm{~s}$ as shown in Fig. 5(d). In addition, no implant related defects were found for any annealing condition of PA-Ge. However, extended defects during the SPEG process is not expected for low $\mathrm{Ge}^{+}$implant fluences and is not expected to form for anneals in excess of $400^{\circ} \mathrm{C} . .^{15,16,18,43}$

The observed activation behavior in both c-Ge and PA$\mathrm{Ge}$ is certainly unique and a far departure from what has been observed previously for $\mathrm{B}^{+}$implants in $\mathrm{Si}$. The ultrashallow nature of the implants in this work suggests that there may be a correlation with surface proximity. It has been suggested that there is a barrier to point defect recombination at the Ge surface which has been shown to spur the formation of a nanoporous structure. ${ }^{44,45}$ In addition, recent reports have noted the Ge surface as acting as a sink for vacancies while reflecting interstitials. ${ }^{38,39}$ With increasing $\mathrm{B}^{+}$implant energy, it has been observed that the active fraction increases with indicates the surface proximity may be affecting the activation behavior.

However, it should also be mentioned that increasing the implant energy also introduces a larger number of Frenkel pairs into the lattice upon implantation and may affect the activation observed in this work as a function of energy. It has been documented before that the activation of $\mathrm{B}$ in $\mathrm{Ge}$ is highly dependent on the damage imparted into the crys$\mathrm{tal}^{8,9}$ and similar findings have been observed in this work. In essence, increasing the $\mathrm{B}^{+}$fluence at a fixed energy introduces a fixed amount of damage to the lattice per $\mathrm{B}$ ion. Increasing the fluence allows for more B atoms to become electrically active although at a fixed percentage of the fluence. However, increasing the energy creates more damage per incoming ion which allows for an increase in the fraction of active dopants as observed in this work. It is believed that the introduction of additional Frenkel pairs and the reduction of the effects of the surface proximity on vacancy annihilation allow for an increase in the fraction of activated dopants with increasing $\mathrm{B}^{+}$energy.

\section{CONCLUSIONS}

The electrical activation of ultra-shallow $\mathrm{B}^{+}$implants in c-Ge and PA-Ge was investigated using micro Hall effect and ion beam analysis techniques following isochronal anneals between 400 and $600^{\circ} \mathrm{C}$. A large fraction of implanted dopant was electrically inactive for all investigated conditions which suggest the presence of a stable $\mathrm{B}-\mathrm{Ge}$ cluster in both c-Ge and PA-Ge. With increasing annealing temperature, slight activation changes were observed, but a large discrepancy from full activation exists for all investigated fluences and implant energies. With increasing implant energy from 2 to $6 \mathrm{keV}$, the fraction of electrically active $\mathrm{B}$ atoms increased which suggests that surface proximity and its effects on vacancy annihilation may 
be impacting the $\mathrm{B}$ activation. The results suggest that the activation of $\mathrm{B}$ in $\mathrm{Ge}$ is highly dependent on the point defect environment which may promote the formation of an inactive B complex.

\section{ACKNOWLEDGMENTS}

The authors acknowledge the Intel Corporation for funding this work and the Major Analytical Instrumentation Facility at the University of Florida for the use of the FIB and TEM facilities. CINF is sponsored by The Danish National Research Foundation. Sandia is a multiprogram laboratory operated by Sandia Corporation, a Lockheed Martin Company, for the United States Department of Energy under Contract No. DE-AC04-94AL85000.

${ }^{1}$ E. E. Haller, Mater. Sci. Semicond. Process. 9, 408-422 (2006).

${ }^{2}$ M. Heyns and W. Tsai, MRS Bull. 34, 485 (2009).

${ }^{3}$ C. Claeys, J. Mitard, G. Eneman, M. Meuris, and E. Simoen, Thin Solid Films 518, 2301 (2010).

${ }^{4}$ M. Heyns, A. Alian, G. Brammertz, M. Caymax, Y. C. Chang, L. K. Chu, B. De Jaeger, G. Eneman, F. Gencarelli, G. Groeseneken, G. Hellings, A. Hikavyy, T. Y. Hoffmann, M. Houssa, C. Huyghebaert, D. Leonelli, D. Lin, R. Loo, W. Magnus, C. Merckling, M. Meuris, J. Mitard, L. Nyns, T. Orzali, R. Rooyackers, S. Sioncke, B. Soree, X. Sun, A. Vandooren, A. S. Verhulst, B. Vincent, N. Waldron, G. Wang, W. E. Wang, and L. Witters, in 2011 IEEE International Electron Devices Meeting (IEDM) (2011), p. 13.1.1.

${ }^{5}$ C. O. Chui, K. Gopalakrishnan, P. B. Griffin, J. D. Plummer, and K. C. Saraswat, Appl. Phys. Lett. 83, 3275 (2003).

${ }^{6}$ Y.-L. Chao, S. Prussin, J. C. S. Woo, and R. Scholz, Appl. Phys. Lett. 87, 142102 (2005).

${ }^{7}$ S. Mirabella, G. Impellizzeri, A. M. Piro, E. Bruno, and M. G. Grimaldi, Appl. Phys. Lett. 92, 251909 (2008).

${ }^{8}$ E. Bruno, G. Impellizzeri, S. Mirabella, A. M. Piro, A. Irrera, and M. G. Grimaldi, Mater. Sci. Eng., B 154-155, 56 (2008).

${ }^{9}$ G. Impellizzeri, S. Mirabella, E. Bruno, A. M. Piro, and M. G. Grimaldi, J. Appl. Phys. 105, 063533 (2009).

${ }^{10}$ Y. S. Suh, M. S. Carroll, R. A. Levy, G. Bisognin, D. De Salvador, M. A. Sahiner, and C. A. King, IEEE Trans. Electron Devices 52, 2416 (2005).

${ }^{11}$ F. Panciera, P. F. Fazzini, M. Collet, J. Boucher, E. Bedel, and F. Cristiano, Appl. Phys. Lett. 97, 012105 (2010).

${ }^{12}$ S. Uppal, A. F. W. Willoughby, J. M. Bonar, A. G. R. Evans, N. E. B. Cowern, R. Morris, and M. G. Dowsett, J. Appl. Phys. 90, 4293 (2001).

${ }^{13}$ S. Uppal, A. F. W. Willoughby, J. M. Bonar, A. G. R. Evans, N. E. B. Cowern, R. Morris, and M. G. Dowsett, Physica B 308-310, 525 (2001).

${ }^{14}$ S. Uppal, A. F. W. Willoughby, J. M. Bonar, N. E. B. Cowern, T. Grasby, R. J. H. Morris, and M. G. Dowsett, J. Appl. Phys. 96, 1376 (2004)

${ }^{15}$ A. Satta, E. Simoen, T. Clarysse, T. Janssens, A. Benedetti, B. De Jaeger, M. Meuris, and W. Vandervorst, Appl. Phys. Lett. 87, 172109 (2005).

${ }^{16}$ A. Satta, E. Simoen, T. Janssens, T. Clarysse, B. D. Jaeger, A. Benedetti, I. Hoflijk, B. Brijs, M. Meuris, and W. Vandervorst, J. Electrochem. Soc. 153, G229 (2006).

${ }^{17}$ A. Satta, A. D’Amore, E. Simoen, W. Anwand, W. Skorupa, T. Clarysse, B. Van Daele, and T. Janssens, Nucl. Instrum. Methods Phys. Res. B 257, 157 (2007).

${ }^{18}$ E. Simoen, G. Brouwers, A. Satta, M.-L. David, F. Pailloux, B. Parmentier, T. Clarysse, J. Goossens, W. Vandervorst, and M. Meuris, Mater. Sci. Semicond. Process. 11, 368 (2008).
${ }^{19}$ E. Simoen, A. Satta, A. D'Amore, T. Janssens, T. Clarysse, K. Martens, B. De Jaeger, A. Benedetti, I. Hoflijk, B. Brijs, M. Meuris, and W. Vandervorst, Mater. Sci. Semicond. Process. 9, 634 (2006).

${ }^{20}$ B. R. Yates, B. L. Darby, N. G. Rudawski, K. S. Jones, D. H. Petersen, O. Hansen, R. Lin, P. F. Nielsen, and A. Kontos, Mater. Lett. 65, 3540 (2011).

${ }^{21}$ G. Hellings, E. Rosseel, T. Clarysse, D. H. Petersen, O. Hansen, P. F. Nielsen, E. Simoen, G. Eneman, B. De Jaeger, T. Hoffmann, K. De Meyer, and W. Vandervorst, Microelectron. Eng. 88, 347 (2011).

${ }^{22}$ G. Bisognin, S. Vangelista, M. Berti, G. Impellizzeri, and M. G. Grimaldi, J. Appl. Phys. 107, 103512 (2010).

${ }^{23}$ P. M. Fahey, P. B. Griffin, and J. D. Plummer, Rev. Mod. Phys. 61, 289 (1989).

${ }^{24}$ P. A. Stolk, H.-J. Gossmann, D. J. Eaglesham, D. C. Jacobson, C. S. Rafferty, G. H. Gilmer, M. Jaraíz, J. M. Poate, H. S. Luftman, and T. E. Haynes, J. Appl. Phys. 81, 6031 (1997).

${ }^{25}$ F. Severac, F. Cristiano, E. Bedel-Pereira, P. F. Fazzini, W. Lerch, S. Paul, X. Hebras, and F. Giannazzo, J. Appl. Phys. 105, 043711 (2009).

${ }^{26}$ M. Aboy, L. Pelaz, E. Bruno, S. Mirabella, and S. Boninelli, J. Appl. Phys. 110, 073524 (2011).

${ }^{27}$ B. L. Doyle and D. K. Brice, Nucl. Instrum. Methods Phys. Res. B 35, 301 (1988).

${ }^{28}$ T. Clarysse, J. Bogdanowicz, J. Goossens, A. Moussa, E. Rosseel, W. Vandervorst, D. H. Petersen, R. Lin, P. F. Nielsen, O. Hansen, G. Merklin, N. S. Bennett, and N. E. B. Cowern, Mater. Sci. Eng., B 154-155, 24 (2008).

${ }^{29}$ D. H. Petersen, O. Hansen, R. Lin, and P. F. Nielsen, J. Appl. Phys. 104, 013710 (2008).

${ }^{30}$ D. H. Petersen, O. Hansen, T. M. Hansen, P. Boggild, R. Lin, D. Kjaer, P. F. Nielsen, T. Clarysse, W. Vandervorst, E. Rosseel, N. S. Bennett, and N. E. B. Cowern, J. Vacuum Sci. Technol. B 28, C1C27 (2010).

${ }^{31}$ L. Romano, A. M. Piro, S. Mirabella, M. G. Grimaldi, and E. Rimini, Appl. Phys. Lett. 87, 201905 (2005).

${ }^{32}$ A. M. Piro, L. Romano, S. Mirabella, and M. G. Grimaldi, Mater. Sci. Eng., B 124-125, 249 (2005).

${ }^{33}$ L. Romano, A. M. Piro, V. Privitera, E. Rimini, G. Fortunato, B. G. Svensson, M. Foad, and M. G. Grimaldi, Nucl. Instrum. Methods Phys. Res. B 253, 50 (2006).

${ }^{34}$ L. Romano, A. M. Piro, M. G. Grimaldi, and E. Rimini, Nucl. Instrum. Methods Phys. Res. B 249, 181 (2006).

${ }^{35}$ L. Romano, A. M. Piro, S. Mirabella, and M. G. Grimaldi, Phys. Rev. B 81, 075210 (2010)

${ }^{36}$ R. J. Kaiser, S. Koffel, P. Pichler, A. J. Bauer, B. Amon, L. Frey, and H. Ryssel, Microelectron. Eng. 88, 499 (2011).

${ }^{37}$ J. F. Ziegler, Nucl. Instrum. Methods Phys. Res. B 219-220, 1027 (2004).

${ }^{38}$ H. Bracht, S. Schneider, J. N. Klug, C. Y. Liao, J. L. Hansen, E. E. Haller, A. N. Larsen, D. Bougeard, M. Posselt, and C. Wündisch, Phys. Rev. Lett. 103, 255501 (2009).

${ }^{39}$ G. G. Scapellato, S. Boninelli, E. Napolitani, E. Bruno, A. J. Smith, S. Mirabella, M. Mastromatteo, D. De Salvador, R. Gwilliam, C. Spinella, A. Carnera, and F. Priolo, Phys. Rev. B 84, 024104 (2011).

${ }^{40}$ A. F. Saavedra, K. S. Jones, M. E. Law, K. K. Chan, and E. C. Jones, J. Appl. Phys. 96, 1891 (2004).

${ }^{41}$ S. M. Sze and K. K. Ng, Physics of Semiconductor Devices (John Wiley and Sons, 2007).

${ }^{42}$ D. P. Hickey, Z. L. Bryan, K. S. Jones, R. G. Elliman, and E. E. Haller, J. Vacuum Sci. Technol. B 26, 425 (2008).

${ }^{43}$ A. Satta, T. Janssens, T. Clarysse, E. Simoen, M. Meuris, A. Benedetti, I. Hoflijk, B. D. Jaeger, C. Demeurisse, and W. Vandervorst, J. Vacuum Sci. Technol. B 24, 494 (2006).

${ }^{44}$ L. Romano, G. Impellizzeri, M. V. Tomasello, F. Giannazzo, C. Spinella, and M. G. Grimaldi, J. Appl. Phys. 107, 084314 (2010).

${ }^{45}$ B. R. Yates, B. L. Darby, R. G. Elliman, and K. S. Jones, Appl. Phys. Lett. 101, 131907 (2012). 